\title{
A Inserção da Mulher no Futebol
}

\section{The Insertion of Women in Soccer}

\section{Anna Tharyne de Almeida Nascimento ${ }^{1 *}$, Fátima Niemeyer da Rocha ${ }^{2}$ \\ Como citar esse artigo.NASCIMENTO, \\ Resumo} A. T. A.; DA ROCHA, F. N. A Inserção da Mulher no Futebol. Mosaico - Revista Multidisciplinar de Humanidades, Vassouras, v. 12, n. 2, p. 69-77, mai./ ago. 2021.

Nota da Editora. Os artigos publicados na Revista Mosaico são de responsabilidade de seus autores. As informações neles contidas, bem como as opiniões emitidas, não representam pontos de vista da Universidade de Vassouras ou de suas Revistas.
Estudo de abordagem qualitativa, de caráter transversal e analítico, cuja amostra foi composta de 17 (dezessete) mulheres praticantes de futebol feminino amador, com idade entre 18 e 32 anos, residentes no Estado do Rio de Janeiro. O estudo teve como objetivo investigar os sentimentos suscitados nas mulheres quando da sua inserção e participação no futebol feminino. Além disso, investigou o papel da Psicologia do Esporte na inclusão da mulher nesse esporte. Os problemas de base que nortearam a investigação envolveram as seguintes indagações: de que forma as mulheres se sentem ao se inserirem num esporte predominantemente masculino? Qual é o papel da Psicologia do Esporte na inclusão da mulher nesse contexto? Mesmo com o aumento significativo, nos últimos anos, da participação das mulheres nesse universo masculinizado, o papel feminino ainda tem pouca visibilidade. A metodologia utilizada envolveu um questionário com 10 (dez) questões abertas. Os resultados apontaram para uma mudança no processo de inclusão da mulher no futebol feminino, associada a uma maior liberdade da mulher na prática desse esporte. Mesmo esse espaço esportivo sendo um ambiente de domínio masculino e repleto de preconceitos a figura feminina vem ganhando espaço e conseguindo de forma gradativa consolidar condições adequadas para sua prática no futebol feminino.

Palavras-chave: Mulher; Futebol; Inclusão; Psicologia do Esporte.

\begin{abstract}
This is a qualitative, cross-sectional and analytical study, whose sample consisted of 17 (seventeen) female amateur soccer players, aged between 18 and 32, residing in the State of Rio de Janeiro. The study aimed to investigate the feelings aroused in women when they were inserted and participated in women's soccer. In addition, it investigated the role of Sport Psychology in the inclusion of women in this sport. The underlying problems that guided the research involved the following questions: How do women feel about engaging in a predominantly male sport? What is the role of Sport Psychology in the inclusion of women in this context? Even with the significant increase in the participation of women in this masculinized universe in recent years, the female role still has little visibility. The methodology used involved a questionnaire with 10 (ten) open questions. The results pointed to a change in the process of inclusion of women in women's football, associated with greater freedom of women in the practice of this sport. Even though this sporting space is an environment of male dominance and full of prejudice, the female figure has been gaining space and gradually consolidating conditions suitable for their practice in women's football.

Keywords: Woman; Soccer; Inclusion; Sport Psychology.
\end{abstract}

\section{Introdução}

O esporte, na qualidade de instituição social, desde o final de século XX, vem implementando em volta de si várias áreas designadas como as ciências do esporte. Nesse âmbito se encontra a Psicologia do Esporte, cuja história no Brasil já dispõe de quase um século (RUBIO, 2000). Essa área da Psicologia vem protagonizando estudos que abordam a personalidade, a motivação, a dinâmica de grupo, a liderança e o bem-estar de atletas, representando um ambiente de perspectiva social (RUBIO,1999).

Definida por Weinberg e Gould (1995), a Psicologia do Esporteé uma ciência que estuda elementos psicológicos relacionados a várias categorias de atividade física. Os profissionais da área têm interesse em auxiliar os atletas a usar os ensinamentos psicológicos para aperfeiçoar suas performances e entender que a atuação no esporte influencia o desenvolvimento psicológico.

Nesta perspectiva, o tema central deste estudo aborda a inclusão da mulher no cenário de atividades físico-desportivas, em especial no futebol feminino. A participação da mulher, atualmente, nesse esporte, tem demostrado uma efetiva e crescente autonomia, isto é, vem se configurando como um movimento autônomo da mulher que se inclú na realidade do esporte, independente de determinações sociais e atendendo a seus próprios anseios e desejos (MOURÃO, 2000).

\section{Afiliação dos autores}

${ }^{1}$ Graduanda em Psicologia, Curso de Psicologia, Universidade de Vassouras, Vassouras, RJ, Brasil

${ }^{2}$ Especialista em Psicologia Social pela PPGPA/ISOP/Fundação Getúlio Vargas; mestre em história pela Universidade Severino Sombra/Vassouras; Doutora em psicologia pela UFRJ, Vassouras, RJ, Brasil. 
Outro aspecto que inspirou essa pesquisa foi o fato de que a literatura sobre o espaço da mulher dentro do esporte é escassa: "quando voltamos nossa atenção para a área de estudos sobre mulher e relações de gênero que vem se constituindo com força no Brasil nos últimos anos, o cenário é de penúria" (DUNNING, 1994, p. 163).

Além disso, o futebol feminino, até os dias de hoje, é cercado de preconceito, mesmo tendo sua visibilidade ampliada nos últimos tempos. Em 1898, em Londres, ocorreu a primeira partida entre Inglaterra x Escócia. E no Brasil há registros de partidas com mulheres e homens no período de 1908 e 1909. Porém, oficialmente, o primeiro jogo de futebol feminino ocorreu em 1921, em São Paulo, no bairro de Tremembé, o qual foi noticiado pelo jornal Gazeta como um evento "curioso". Nesse momento, verificamos que o preconceito contra a participação das mulheres no futebol era nítido, por ser considerado um esporte que não era feito para mulheres, já que era um esporte bruto e impróprio, principalmente no olhar das famílias conservadoras. Inclusive, foi baixado um decreto do Estado Novo com o impedimento de esportes "contrários a natureza das mulheres" (FUTEBOL FEMININO NO BRASIL, 2019, p.1).

Segundo Goellner (2006) o esporte designa um espaço que retrata costumes e argumentos, que estabelece comportamentos com base no que cada cultura estipula como feminino ou masculino, proporcionando novos formatos na convivência entre os sexos; daí surgiram, então, os atuais conceitos culturais sobre a atuação das mulheres no espaço esportivo.

As mulheres viveram rejeitadas e silenciadas em muitos momentos da história e por um longo tempo. Para Perrot (2005) existem duas justificativas para o papel invisível da mulher na história: primeiramente, a sua baixa visibilidade em áreas públicas, o que era de interesse da sociedade patriarcal; em segundo lugar, as mulheres dispunham de um alcance restrito a fontes escritas a respeito do esporte, pois suas atividades domésticas "deveriam" estar sempre em primeiro lugar.

Um outro fator significativo é que a figura da mulher foi, por muito tempo, vista e descrita de um ponto de vista masculino, a partir de um olhar generalizado. Perrot $(2005$, p. 17) sustenta que: "É claro que falam das mulheres, mas generalizando. 'As mulheres são...', 'A mulher é...'. A prolixidade do discurso sobre as mulheres contrasta com a ausência de informações precisas e circunstanciadas". Matos (1997) evidencia que foi somente na década de 1970 que as mulheres "roubaram a cena" e se fizeram visíveis, obtendo seu espaço na sociedade; tal movimento resultou em vários estudos e pesquisas sobre as mulheres.

Segundo Alves e Pitanguy (1991) durante o século XIX a mulher era dominada pelo homem; ela devia acatar as regras de seu pai ou marido, vivendo em privação. Com o movimento feminista as mulheres passaram a ter o seu espaço e direitos e o capitalismo contribuiu para que a mulher conquistasse um espaço maior através do trabalho. Mesmo com o capitalismo colaborando com a entrada das mulheres em alguns espaços, encontramos autoras que contestam o fato do movimento feminista estar ligado ao capitalismo.

O capitalismo é a barbárie. Transforma tudo em mercadorias: corpos, talentos, fé, trabalho, amor, desejos, mulheres. Não nos serve, por isso, o feminismo neoliberal que não tem como horizonte a superação, por exemplo, da exploração de trabalhadoras domésticas, de mulheres como Dona Nininha. Por isso o feminismo das $99 \%$ é radicalmente anticapitalista. (ARRUZZA; BHATTACHARYA; FRASER, 2019, p. 17)

A obra "Feminismo para os 99\%: um manifesto" (ARRUZZA; BHATTACHARYA; FRASER, 2019) procura firmar a defesa de um feminismo emancipatório, que refuta o entendimento universal da categoria de mulher em que se considere todas as mulheres. Aponta paraum movimento feminista anticapitalista, antirracista, ecossocialista, antiLGBTfóbico e internacionalista.

Em relação a diferença salarial entre os gêneros, quando se fala em futebol os números são maiores para os homens. De acordo com a revista francesa France Football a jogadora de futebol eleita melhor do mundo recebe 325 vezes menos que o jogador que obtém o mesmo título. (GEOVANA, 2019)

Para a grande maioria das mulheres resta um trabalho mal remunerado e, por vezes, sem direitos trabalhistas. Além disso, ainda corre o risco de sofrer com os assédios e abusos nos locais de trabalho. $\mathrm{Na}$ maior parte dos casos, o salário não cobre os custos de reprodução social, fazendo com que a mulher trabalhe em vários empregos e acabe sendo negligenciada pelo Estado. (ARRUZZA; BHATTACHARYA; FRASER, 2019).

E em relação a subjetividade do corpo feminino houve transformações históricas, sociais, políticas e culturais, uma vez que no patriarcado as atribuições das mulheres eram direcionadas a reprodução e sempre estando expostas a autoridade masculina. Notamos, então, que foi através das mudanças socioculturais e políticas que se constituiu a subjetividade sobre o corpo da mulher, organizando seu jeito de existir em relação ao mundo.

Do universo privado do lar ao ambiente social público, da função doméstica ao trabalho com retorno financeiro, esses espaços foram alcançados através de ações de resistência com as quais as mulheres foram buscando oportunidades iguais em relação ao homem (MARTIN, 2006). Embora com o progresso do empoderamento feminino, poucos tópicos referentes a vivência da mulher passaram a ser vistos de forma mais livre; a sua atuação no esporte foi uma dessas 
questões, porém sempre envolvida em preconceitos, especificamente o futebol, sempre definido pelo comparecimento masculino. Esse ambiente vai além de ser somente um espaço esportivo, podendo ser reconhecido como um espaço social (ECOTEN; CORSETTI, 2010).

A inclusão e a continuação da mulher no meio esportivo aconteceram de modo gradativo, mas confuso. Entre os séculos XIX e XX, as mulheres até praticavam esportes, como, por exemplo, o hockey, o boxe e o rugby, mesmo sabendo que se tratava de um ambiente masculinizado, e se dispondo a estar na contramão do cenário socio-histórico - e isso era visto como algo inadequado, como esclarece Goellner (2006). De acordo com Dunning (1994), possivelmente, as mulheres quando buscam o esporte se influenciam por duas razões: a primeira seria o benefício em alcançar bem-estar social e a variabilidade de atividades que o esporte pode trazer, junto com os benefícios associados ao autoconceito e a identificação; e em segundo, a equidade de possibilidades como contraponto às restrições colocadas, ao longo dos anos, aos comportamentos femininos.

$\mathrm{O}$ espaço das mulheres brasileiras no âmbito do esporte foi sempre carregado de pressões. Os movimentos moralizadores no século XIX marcaram de forma negativa esse espaço da mulher, inclusive com a oposição do Conselho Nacional do Desporto CND (BRASIL, 1941): “Às mulheres não se permitirá a prática de desportos incompatíveis com as condições de sua natureza, devendo para este efeito o CND baixar as necessidades de instruções às entidades desportivas do país". Em 1965, aconteceu outra proibição: às mulheres "não é permitida a prática de lutas de qualquer natureza, futebol, futebol de salão, futebol de praia, polo aquático, rugby, halterofilismo e baseball" (ZEFERINO; SALLES, 2009, p. 4).

Para Goellner (2005) essa desaprovação era fundamentada na ideia da proteção da fecundidade, da integridade física da mulher e do medo de perda do espaço masculino. Para Lenskyj (1986 apud ADELMAN, 2003, p. 5)

a habilidade esportiva dificilmente se compatibilizava com a subordinação feminina tradicional da sociedade patriarcal; de fato, o esporte oferecia a possibilidade de tornar igualitárias as relações entre os sexos. O esporte, ao minimizar as diferenças socialmente construídas entre os sexos, revelava o caráter tênue das bases biológicas de tais diferenças; portanto, constituía uma ameaça séria ao mito da fragilidade feminina.

No Brasil, desde 1930, há relatos do futebol feminino nos estados do Rio de Janeiro e de São Paulo; mesmo sendo referenciado como "país do futebol", são escassos os estudos que procedem sobre este assunto. E o futebol feminino continua sendo envolto em um composto de regras e reprovações. (FRANZINI, 2005)

A mulher tem enfrentado inúmeros obstáculos em relação a sua atuação no futebol feminino, como o preconceito, sempre encontrando muitos impedimentos quando se refere a sua atuação. A sociedade em geral tem uma responsabilidade grande nessa realidade, na qual a imagem feminina se destaca do ponto de vista estético ao invés de uma ótica esportista (SILVA, 2012). A erotização dos corpos femininos e a apelação à beleza das jogadoras sustentou a justificativa de que, se as mulheres fossem atraentes, consequentemente atrairia um maior público aos jogos e recursos através de patrocínios, cuja falta traz uma grande dificuldade ao meio esportivo (MULHERES..., 2003, p. 42).

Enfim, sendo o ambiente do futebol desde sempre configurado como um ambiente predominantemente masculino, que vai além do cenário esportivo, englobando o espaço sociocultural, seus princípios se constituíram como limites para as mulheres. E o acesso da mulher a esse espaço vem revolucionando suas regras e se apresentando como uma ameaça aos comportamentos machistas e sexistas (FRANZINI, 2005).

A história da Psicologia do Esporte remonta ao início do século XX, no Estados Unidos e na Rússia; no Brasil, especificamente, surge na Copa do Mundo de Futebol de 1958 (RUBIO, 2000). Williams e Straud (1991, p. 30) sustentam que a Psicologia do Esporte, como assimilação e percepção de técnicas psicológicas aplicadas no esporte, tem o propósito de potencializar a evolução e o rendimento pessoal. E para Weinberg e Gould (1995) é uma ciência que engloba fatores psicológicos correlacionados a exercícios e diferentes atividades físicas. Os especialistas em psicologia do esporte têm o intuito de auxiliar os atletas a usar elementos psicológicos ao seu favor para melhorar seu rendimento e entender como o esporte influencia o bemestar psicológico.

De acordo com Brawley, Carron e Widmeyer (1993) um grupo esportivo pode ser considerado um dos mais importantes e influentes grupos com os quais a pessoa irá relacionar-se. Por ser cotidiano na vida da sociedade, e em várias culturas, o futebol é um acontecimento socializante. A psicologia do esporte, então, conforme Rubio (2007), não atua somente no alto rendimento, com os grupos que se exercitam frequentemente para competições, mas também com os que buscam metas de superação sem necessariamente ter um oponente. Em se tratando de rendimento, todas as aplicações são voltadas para o aproveitamento máximo do indivíduo e da equipe, para tentar eliminar os pontos fracos e potencializar os pontos positivos e esperados.

Não é incomum aparecerem demandas dos atletas que não estão associadas ao ambiente de competições, mas $\operatorname{sim}$ a dificuldades pessoais que afetam seu rendimento, o que pode nos fazer pensar se o profissional vai entrar no cenário clínico, afastando-se do esporte. Porém, nesse sentido, não se trata necessariamente de afastar a Psicologia do Esporte de sua natureza, pois ela 
é Psicologia antes de mais nada. E quando falamos sobre atendimento clínico no ramo do esporte não estamos nos referindo a uma técnica psicoterápica tradicional em um consultório; a intervenção clínica no esporte tratase de buscar solução para os embates do sujeito-atleta, para potencializar seu rendimento esportivo (RUBIO, 2007).

Nessa perspectiva, o estudo procurou confirmar a hipótese de que ao se inserir num esporte predominantemente masculino a mulher se sente alvo de preconceito e exclusão. Teve como objetivo geral: compreender a maneira como as mulheres se sentem ao se inserirem num esporte predominantemente masculino; e como objetivos específicos: entender a percepção das mulheres que se inserem no futebol feminino; e perceber a importância da Psicologia do Esporte na área de futebol feminino.

Além disso, o estudo foi desenvolvido dentro dos princípios e normas éticos que regulamentam a pesquisa com seres humanos, tendo sido aprovado pelo Comitê de Ética em Pesquisa da Universidade de Vassouras, conforme o Parecer CAAE no 19429919.0.0000.5290.

\section{Metodologia}

Trata-se de um estudo com abordagem qualitativa, de caráter transversal e analítico, que buscou responder aos seguintes questionamentos: de que forma as mulheres se sentem ao se inserirem num esporte predominantemente masculino? Qual é o papel da Psicologia do Esporte na inclusão da mulher nesse contexto?

A amostra foi composta por 17 (dezessete) participantes, do sexo feminino, com idade entre 18 e 32 anos, praticantes de futebol feminino amador, residentes no Estado do Rio de Janeiro.

Os instrumentos de coleta de dados incluíram: uma Ficha de Informações Sociodemográficas, para coleta de informações sobre: idade, estado civil, escolaridade, profissão/ocupação e renda; e um Questionário/Roteiro de Entrevista, composto de 10 questões, que admitiram mais de uma resposta cada.

Os procedimentos de coleta dos dados incluíram as informações sobre o tema e objetivos da pesquisa, a garantia da preservação do sigilo quanto às identidades das participantes, da privacidade e da autonomia para a participante se desligar do projeto se e quando desejasse, além do acesso a esclarecimentos adicionais, seguido da assinatura do Termo de Consentimento Livre e Esclarecido (TCLE). Os instrumentos de coleta de dados admitiram a auto aplicação, individualmente, ou foram aplicados pela pesquisadora através de entrevista.

\section{Análise e discussão dos resultados}

Os dados levantados pela Ficha de Informações Sociodemográficas foram tabulados em termos de porcentagens relativamente ao número de participantes. E os dados coletados pelo Questionário/Roteiro de Entrevista foram interpretados segundo os propósitos qualitativos da pesquisa, partindo do seu confronto com os conceitos teóricos obtidos pelos métodos Documental e Bibliográfico e os objetivos estabelecidos para o estudo. Os resultados foram representados por métodos estatísticos simples, como frequência de resposta, médias e porcentagens.

Segundo as informações sociodemográficas, na categoria IDADE, $3(17,6 \%)$ entrevistadas estão na faixa etária de 18 a 20 anos, $7(41,1 \%)$ entre 21 a 23 anos, $3(17,6 \%)$ entre 24 a 26 anos, $1(5,8 \%)$ entre 27 a 29 anos e $2(11,7 \%)$ na faixa etária entre 30 a 32 anos.

$\mathrm{Na}$ categoria ESTADO CIVIL, 15 (88,3\%) mulheres são solteiras e $2(11,7 \%)$ casadas (ou vive com companheiro/a); as demais possibilidades de estado civil (divorciada, separada, desquitada, viúva) não foram apontadas.

Sobre a categoria ESCOLARIDADE, 2 (11,7\%) entrevistadas possuem o Ensino Médio Incompleto, 4 $(23,55 \%)$ o Ensino Médio Completo, 8 (47\%) o Ensino Superior Incompleto, $2(11,7 \%)$ o Ensino Superior Completo, $1(5,8 \%)$ a Pós-Graduação Incompleta.

$\mathrm{Na}$ categoria PROFISSÃO/OCUPAÇÃO, a ocupação "Atleta" obteve $2(11,7 \%)$ respostas, "Estudante" somou 10 (58,8\%) respostas, "Professora" obteve $2(11,7 \%)$ respostas e "Não Respondeu" somou $3(17,6 \%)$ respostas.

A categoria NÍVEL DE RENDA, teve variação entre "Salário Mínimo" com $6(35,2 \%)$ respostas e a faixa de 01 a 03 (41,1\%) "Salários Mínimos" 7 respostas; $4(23,5 \%)$ participantes não responderam.

A análise dos conteúdos encontrados nas respostas ao questionário possibilitou o surgimento de categorias a partir da Análise de Conteúdo, conforme proposta por Bardin (2011), com os resultados representados pela frequência das respostas.

Das repostas para a "Questão 1 - Por que você decidiu praticar futebol", a categoria que mais apareceu foi SEMPRE GOSTEI DE PRATICAR ESPORTE com 5 respostas, seguida de AMOR, que obteve 4 respostas; PAIXÃO e INFLUÊNCIA FAMILIAR obtiveram 2 respostas cada; já as categorias QUERIA PRATICAR ALGUM ESPORTE, BOA ATIVIDADE FÍSICA, CURIOSIDADE, SEMPRE PRATIQUEI, LAZER, RELAXAR e ESPORTE FAVORITO obtiveram 1 resposta cada.

O futebol não é, quando visto em sua totalidade, apenas um esporte; ele abrange diversas manifestações, sendo elas psicológicas, biológicas, 
culturais e sentimentais. Para Vallerand (2008), um dos sentimentos que se pode levar em consideração para a escolha deste esporte é a paixão. Pode-se entender como paixão uma ocupação que o ser humano escolhe para gastar seu tempo e disposição. E o comprometimento com essa atividade pode ser tão grande que se torna a particularidade mais evidente da identidade do sujeito. "[...] ser apaixonado por um esporte leva os indivíduos a se dedicarem intensamente para seu esporte, permitindo que persistam mesmo em face de obstáculos e que alcancem, eventualmente, a excelência"(VALLERAND, 2008, p. 374).

A influência familiar é um outro fator que pode levar a pessoa há alguma prática esportiva, sendo uma questão motivacional muito importante. Gallahue e Ozmun (2003) apontam para alguns motivos que fazem os jovens desde cedo optarem por algum esporte, entre os quais estão a vontade de ser parte de algum grupo, o aperfeiçoamento de habilidades e o aumento da viabilidade para competir.

Nas repostas para a "Questão 2 - Na sua opinião, praticar esse esporte interfere de alguma forma em seu convívio social?" a resposta SIM foi dada por 8 participantes, confirmando a ideia de que esse esporte interferiu no seu convívio social; 7 participantes responderam que NÃO, 1 entrevistada respondeu que, ATUALMENTE, NÃO INTERFERE, do que se pode inferir que interferiu no passado, e 1 participante afirmou que INTERFERE UM POUCO. Como justificativas positivas dessa interferência surgiram as categorias o BEM-ESTAR FÍSICO com 3 respostas e INTERESSE EM COMUM e ALÍVIO DE ESTRESSE com 2 respostas cada; com 1 resposta cada temos as categorias DISCIPLINA, UNIÃO, RESPEITO, BEM-ESTAR MENTAL e AMPARO; PROBLEMAS FAMILIARES obteve 1 resposta, assim como MUITOS QUESITOS também com 1 resposta.

Segundo Gould (apud SCALON; BECKER JR.; BRAUNER, 1999) é possível identificar os fatores que influenciam a prática desportiva através do incremento no bem-estar físico, pela formação de amizades e no aperfeiçoamento de habilidades, assim como no desenvolvimento físico. Considerando o aspecto psicossocial, conforme Weinberg e Gould (2001), o aumento da autoestima, o alívio do estresse, um maior bem-estar e a diminuição do isolamento social são resultados positivos que podem ser alcançados através do esporte.

Na "Questão 3 - Você sofreu algum preconceito por praticar futebol? Se sim, cite uma situação que tenha sido constrangedora ou preconceituosa que você vivenciou por praticar esse esporte", 12 mulheres relataram terem sofrido algum tipo de PRECONCEITO, enquanto 3 participantes disseram que NÃO e 1 respondeu que NÃO DIRETAMENTE; quanto as explicações, a categoria APELIDOS MALDOSOS somou 5 respostas, PIADAS obteve 3 resultados, SEM CAPACIDADE 2 respostas, DISCRIMINAÇÃO, DEBOCHES, FOMOS ALVO DE AGRESSÃO PARA DESISTIRMOS e EXCLUSÃO tiveram cada uma 1 resposta.

Ao se averiguar as respostas a essa questão e analisar os relatos de algumas participantes, percebe-se as dificuldades enfrentadas pela mulher ao praticar um esporte predominantemente masculino; nesse cenário, não existem regras sociais que limitem a prática desse esporte por quem quer que seja; porém, mesmo assim, as mulheres são socialmente marginalizadas e são alvo de desconfiança em relação às suas habilidades, apenas por serem mulheres praticando um esporte considerado "masculino" (ROCHA, 2017). Alguns relatos exemplificam as situações de preconceito enfrentadas pelas participantes do estudo: "sofri preconceito sim, alguns como ser chamada de muleque macho, sapatão, entre outros. Como: sai daí que futebol não é para mulher"; "Sim, uma vez falaram para meu marido que eu era lésbica, só por jogar futebol". Na maior parte dos relatos é possível observar palavras como: "macho", "sapatão", "deboche", "coisa de homem", termos que apontam para reações carregadas de agressividade e que envolvem estereótipos. Essas reações a respeito das jogadoras de futebol feminino intensificam, inclusive, o uso de rótulos pejorativos em relação às mesmas.

Nunan (2003, p. 63) esclarece a respeito da interposição desses rótulos: "O rótulo influencia enormemente nossa percepção do comportamento de um indivíduo, pois uma vez atribuído, nós temos a tendência a perceber seu comportamento de acordo com o rótulo imputado, mesmo diante de fatos que o contradigam". Assim, segundo o autor, tais rótulos intervêm na maneira como os outros percebem a conduta dessa mulher, além da tendência a cristalizar tal percepção.

Outro obstáculo enfrentado pela mulher quanto a prática do futebol se refere a sua aceitação social, como os julgamentos negativos e dúvidas sobre a capacidade dessa mulher quanto a ser jogadora de futebol (ROCHA, 2017). "[...] já implicaram com o fato de eu estar no início da prática, aperfeiçoando o movimento. Chegaram a dizer que estavam me dando uma oportunidade de aprender".

A determinação biológica aparece como um argumento que fundamenta o discurso a respeito das desigualdades de gênero, assegurando um menor alcance para a mulher no que tange as atividades sociais em comparação com os homens, principalmente no esporte (DEVIDE, 2005). Como o futebol é um esporte que envolve grande esforço físico, rivalidade, competitividade e liberdade de movimentação, é comum o uso de argumentos discriminatórios a respeito da sexualidade das jogadoras de futebol. E a conduta da mulher que pratica este esporte por vezes é vista como não condizendo com a "normalidade" esperada para pessoas do seu gênero (GOELLNER, 2005). 
Na "Questão 4 - Quais são os pontos positivos de praticar um esporte predominantemente masculino". As respostas ficaram divididas nas seguintes categorias: EMPODERAMENTO com 8 respostas; QUEBRAR TABUS E PROTOCOLOS, DESTACAR-SE, AMIZADES E CONQUISTA DE ESPACOS com 2 respostas cada; e as categorias que obtiveram 1 resposta cada foram RECONHECIMENTO, TALENTO, SENTIMENTO DE FORÇA e PRÁTICA DE UM JEITO MENOS VIOLENTO. Se empoderar através do esporte, para Horochovski e Meirelles (2007, p. 486), "é o processo pelo qual indivíduos, organizações e comunidades angariam recursos que lhes permitam ter voz, visibilidade, influência, capacidade de ação e decisão". E o empoderamento é algo que se manifesta gradativamente dentro de um cenário com poucas ou muitas imposições habituais, sendo, assim, uma conquista contínua e necessária (BRAUNER, 2015).

Quando se fala da inclusão da mulher no cenário esportivo é possível perceber uma significativa diferença de olhar em relação a inclusão da mulher em outros cenários, uma vez que se trata, no esporte, de uma relação entre gêneros. No Brasil, a disputa por espaço entre mulheres e homens no terreno esportivo só não é maior porque, na prática, o processo de inserção da mulher nesse esporte é lento. Atualmente, quando se observa esse território, é possível observar que a mulher está em vários esportes, contemplando de perto as mudanças sociais nesses espaços (MOURÃO, 2005).

Na "Questão 5 - Quais são os pontos negativos de praticar um esporte predominantemente masculino, sendo mulher?" A categoria PRECONCEITO obteve a frequência de 9 respostas; a categoria FALTA DE OPORTUNIDADE somou 3 respostas; INVISIBILIDADE, FALTA DE INCENTIVO, DISCRIMINAÇÃO recebeu 2 respostas por categoria; já as categorias SEXUALIZAÇÃO DOS CORPOS, DESCASO e ESTRUTURA obtiveram 1 voto em cada uma delas; e a categoria NENHUM obteve 5 votos.

É notório que o futebol feminino não desfruta do mesmo reconhecimento que o masculino (FRANZINI, 2005). O preconceito que ele enfrenta está relacionado, em parte, a imposição de a mulher se submeter ao papel de responsável pela reprodução, ou seja, de assumir seu papel de mãe e de "dona de casa". No Brasil, a relação entre os gêneros é definida também pela discriminação e por ideologias que impossibilitam o fim da ideia de que o homem é o sexo forte e mulher, o sexo frágil. Ao longo da história, em relação a mulher, se construiu o pensamento de que esta deveria ficar restrita à esfera doméstica, juntamente com a impossibilidade desta expressar qualquer oposição; porém, já se consegue identificar algumas quebras de tais normas e protocolos (TOJAL, 2003).

Debater sobre esses espaços ainda continua sendo uma dificuldade e, mesmo com o advento dos movimentos feministas, o preconceito, a discriminação e a invisibilidade continuam presentes e frustrando a real liberdade da mulher (TEIXEIRA; CAMINHA, 2013). A desigualdade é um fator importante para o aumento do preconceito e, quando consideramos a desigualdade entre os sexos no futebol, é importante refletir sobre gênero. Ou seja,

Ser do gênero feminino ou masculino leva a perceber o mundo de forma diferente, a estar no mundo de modos diferentes e, em tudo isso há diferenças quanto à distribuição de poder, o que vai significar que o gênero está implicado na concepção e na construção do poder. (DARIDO, 2002, p. 1)

Ainda que esteja ocorrendo o crescimento da participação da mulher no meio esportivo, que elas estejam conquistando cada vez mais seu espaço e superando os estereótipos, os pensamentos antiquados permanecem. A mídia apresenta a vinculação da mulher com o esporte como contraposta a sua vida pessoal e familiar, atribuindo maior importância às suas funções de esposa, mãe e amiga do que ao tempo dispendido com seu talento (ANTÚNEZ, 2001)

Para alcançarem um espaço no futebol as mulheres têm se empenhado muito. Para garantir esse lugar estão enfrentando inúmeros obstáculos, a começar com precisar competir com os privilégios masculinos, passando pelo reduzido número de oportunidades de exibição, assim como de participações em campeonatos e eventos. Até os dias de hoje, convivemos com crenças preconceituosas que questionam a orientação sexual e a feminilidade das atletas (DUNNING; MAGUIRE, 1996). Dessa forma, as mulheres que escolhem ser atletas enfrentam muitos preconceitos e discriminação, em parte devido ao fato de muitas pessoas ligarem a prática de esportes de alto rendimento com a masculinidade (KOLNER, 1995).

Nos meios de comunicação, a figura da mulher no cenário do futebol vem sendo construída diferentemente da imagem masculina, na medida em que os homens têm sido caracterizados pela competitividade, pela força física, pelas conquistas e pelo esforço para jogar mesmo lesionado e, por outro lado, as mulheres são retratadas a partir de uma imagem não-competitiva, pela feminilidade (vinculada a uma ideia de fragilidade) e a uma tendência para cultivar relacionamentos (KOLNER, 1995).

Apesar de as jogadoras de futebol brasileiras estarem,nosúltimosanos, apresentandoótimosresultados em jogos internacionais, tais conquistas permanecem sendo vistas como algo inédito - no sentido de fora do comum - para a maior parte do público (KNIJNIK; VASCONCELLIS, 2003). No entanto, mesmo pouco a pouco, é possível perceber que as conquistas das mulheres nesse âmbito vêm modificando, ao menos em parte, essas ideias pré-estabelecidas, rompendo alguns dos obstáculos que ainda divide os espaços feminino e masculino nesse esporte. 
No Brasil, quando o futebol feminino obtinha alguma visibilidade era através de reportagens esportivas, vinculando a figura da mulher a sua sexualidade e feminilidade. Podemos citar como exemplo, uma reportagem veiculada na revista Placar, em uma das suas edições do mês de julho de 1984, que evidenciou em sua capa a jogadora Vandira, que integrava o time Pinheiros do Paraná, na qual o uso de sua imagem focalizava e explorava a sensualidade feminina. Na reportagem, as atuações das atletas receberam menor atenção, mas suas imagens foram colocadas em evidência, permitindo um olhar machista em relação ao futebol feminino. (LIMA; SOUSA, 2016)

A liberdade das mulheres para a prática do futebol feminino, entretanto, deve ser vista como uma oportunidade para a ruptura de obstáculos sociais e morais que tem sido impostos pela "superioridade" do gênero masculino (LIMA, SOUSA, 2016), o que podemos observar pelas respostas das entrevistadas para a "Questão 6 - Você enfrentou alguma dificuldade quando escolheu esse esporte para a praticar? Se sim, qual ou quais?", em que 11 mulheres relataram já terem enfrentado dificuldades; mas, por outro lado, 6 mulheres disseram que não. As categorias, APOIO FAMILIAR, DISCRIMINAÇÃO E INVISIBILIDADE obteve a mesma frequência, ou seja, 3 respostas para cada categoria e DIFICULDADE FINANCEIRA, ESTRUTURA E PARTICIPAÇÃO FEMININA, 1 resposta cada categoria.

Nesse sentido, Vilani e Samulski (2002, p. 23) argumentam que "os pais influenciam direta e indiretamente a carreira esportiva de seus filhos. A motivação, o estresse, os comportamentos emocionais, dentre outros aspectos, podem estar relacionados ao envolvimento destes neste contexto". Como exemplo, temos alguns relatos das participantes ao se referirem as dificuldades que já foram enfrentadas pela escolha desse esporte: "Sim, principalmente na família, muita discriminação"; "A princípio meus pais não queriam, por causa do preconceito". Para aqueles que praticam esporte, o apoio familiar é fundamental para a continuação dessa atividade, tendo em vista que os estímulos para manter a prática são produzidos pelo ambiente motivacional que se organiza à sua volta. Tais estímulos colaboram para que as atletas consigam atravessar os desafios e impedimentos, pois estão ligados diretamente com a valorização de sua atuação por parte dos familiares, que as ajuda na manutenção da energia motivacional necessária para evitar a sensação de abandono (SERPA, 2003).

Outro fator negativo relevante enfrentado por essas mulheres, além da discriminação sofrida, está ligado a falta de estrutura apropriada, desfavorecendo o futebol feminino. E a mídia acaba colaborando para um tratamento desmerecido dado a esse esporte, distanciando cada vez mais o público do acesso aos jogos (MARTINS; MORAES, 2014), resultando na perpetuação de dificuldades financeiras, patrocínios insuficientes e pouco incentivo para novas participações femininas no futebol.

Apesar de tantas dificuldades, essa modalidade de esporte tem crescido no país. Comparado aos anos anteriores, as mulheres vêm praticando futebol em clubes e áreas de lazer, fazendo com que as competições cresçam conjuntamente. Entretanto, a participação das mulheres em cargos técnicos e administrativos ainda é escassa (LUIZELLI, 2004).

Para Endler (2004) o futebol feminino para ter uma trajetória igual ao masculino ainda tem grandes obstáculos. Porém, mesmo sendo esse percurso um tanto desencorajador, frente a toda a diversidade de dificuldades e a falta de apoio, algumas pessoas ainda têm se esforçado para que o futebol feminino possa ser cada vez mais atrativo no Brasil. A resistência diante dos obstáculo pode ser percebida nas respostas a "Questão 7 - Em algum momento você pensou em desistir dessa prática esportiva por conta de algum preconceito que tenha sofrido?". Dentre as entrevistadas, 5 disseram que já pensaram em desistir do futebol feminino e 12 responderam que NÃO. As categorias MATERNIDADE, ALVO DE PRECONCEITOS e NO INÍCIO DA PRÁTICA, dadas como justificativa, tiveram 1 indicação cada, com respostas como: "Sim, ainda mais depois quando fui mãe"; "No começo, quase sempre"; "Sim, a princípio meus pais não queriam por causa do preconceito".

Para a "Questão 8 - Você pretende continuar praticando esse esporte, mesmo que enfrente alguma dificuldade?", as 17 mulheres entrevistadas (ou seja, todas) disseram que SIM - e nenhuma pretende parar de jogar futebol apesar das adversidades.

$\mathrm{Na}$ "Questão 9 - O que você pensa sobre a atuação de um(a) psicólogo(a) no ambiente do esporte?", a categoria MUITO BOM obteve 4 respostas e a categoria IMPORTANTE obteve 3 respostas; já as categorias INTERESSANTE, NECESSÁRIO e FUNDAMENTAL tiveram 2 respostas cada uma; e tiveram 1 resposta cada as categorias MARAVILHOSO, LEGAL, ESSENCIAL e TRABALHO CONJUNTO.

A atuação do psicólogo do esporte envolve a busca de um melhor entendimento quanto a ação dos fatores psicológicos na performance do atleta e o quão essa ação influencia o bem-estar e a saúde do atleta, por meio de avaliação e análise (WEINBERG; GOULD, 2001). Samulski (2002) aponta para três áreas de atuação do psicólogo do esporte: o ensino - que está direcionado para a prática acadêmica e transmissão de ciência; a pesquisa - que objetiva aperfeiçoar técnicas, teorias e diagnósticos; e a área de aplicação - que envolve o trabalho diretamente com o atleta, por meio de orientação e treinamento.

As respostas para a "Questão 10 - Na sua 
opinião, que tipo de consequência a atuação de um(a) psicólogo(a) no seu time poderia ter?" resultou nas seguintes categorias: BONS RESULTADOS e BONS RENDIMENTOS, cada uma com 3 respostas; com 2 respostas apareceu as categorias MOTIVAÇÃO, AUTOESTIMA, AJUDAR NOS PENSAMENTOS e AJUDA EMOCIONAL; a as categorias ESPAÇO DE FALA, ESTÍMULO, EXCELENTE CONSEQUÊNCIA, TRAZ SEGURANÇA e RELAXAR obtiveram 1 resposta cada.

A Psicologia do Esporte vem se tornando um diferencial e conquistando muitos espaços no ramo do esporte, sendo que vários times brasileiros já dispõem desse trabalho (MARQUES, 2003). Uma das principais atividades realizadas em Psicologia do Esporte envolve o fator motivação, considerada de suma importância no cenário esportivo. A motivação, para Zanetti, Lavoura e Machado (2008) potencializa o comportamento; ou seja, sem a motivação o atleta tem dificuldade de cumprir regras e de continuar seu treinamento todos os dias.

Assim, o trabalho psicológico no âmbito esportivo é fundamental para estimular a disciplina, a confiança e o desempenho (BOMPA, 2002), com o intuito de fortalecer a tanto a parte motivacional, quanto social e cognitiva dos atletas, através da aplicação de técnicas psicológicas paralelamente ao treinamento (SAMULSKI, 2002).

\section{Consideraçoes finais}

Esta pesquisa teve o objetivo de compreender o modo como as mulheres se sentem ao se inserirem num esporte predominantemente masculino. A história do futebol feminino, que sempre foi cercado de preconceitos e teve pouca visibilidade, traz a mulher como uma parte invisibilizada da sociedade patriarcal. Mas, com as mudanças socioculturais e o advento do empoderamento feminino, os espaços, principalmente o esportivo, teve um aumento significativo da participação da mulher.

Um dos mais significativos resultados de nosso estudo foi observar a percepção das mulheres da sua inserção do futebol feminino e a contribuição da Psicologia do Esporte para a sua atuação. Nos resultados apresentados encontramos que as mulheres que escolheram praticar esse esporte, apesar das grandes dificuldades, ainda buscam e lutam por igualdade e reconhecimento.

Através das conquistas gradativas nesse campo de atuação, é possível encontrar interesses em comum com outras mulheres, contribuindo para o bem-estar físico e mental de cada uma, e para conquistar cada vez mais espaços, onde elas ainda são vistas como "algo incomum".

A partir da análise dos discursos das atletas, identificamos que a maior parte acredita que a colaboração da Psicologia do Esporte é de suma importância para o seu desempenho, sendo necessária para auxiliar nos aspectos psicológicos e ajudar a lidar com as dificuldades que enfrentam no seu dia a dia, afim de contribuir de forma positiva na motivação, na autoestima e no suporte emocional.

\section{Referências}

ADELMAN, M. O desafio das amazonas: a construção da identidade de mulheres como atletas e amazonas do hipismo clássico (salto) brasileiro. In: SIMÕES, A. C.; KNIJNICK, J. D. (orgs.). O mundo psicossocial da mulher no esporte: comportamento, gênero, desempenho. São Paulo: Aleph, 2004. p. 277-303.

ALVES, B. M.; PITANGUY, J. O que é feminismo? São Paulo: Brasiliense, 1991. (Coleção Primeiros Passos).

ANTÚNEZ, M. Reflexiones acerca de lo que la mujer representa para el deporte y el verdadero significado del deporte para la mujer. Lecturas: Educación Física y Deportes. Revista Digital, Buenos Aires, v. 7, n. 42 , 2001.

ARRUZZA, C.; BHATTACHARYA, T.; FRASER, N. Feminismo para os 99\%: um manifesto. Trad. de Heci Regina Candiani. São Paulo: Boitempo, 2019.

BARDIN, L. Análise de conteúdo. Lisboa: Edições 70, 2011. (não parece no texto).

BOMPA, T. O. Periodização: teoria e metodologia do treinamento. 4. ed. São Paulo: Phorte, 2002.

BRASIL. Conselho Nacional de Desportos. Decreto-Lei no.3199, de 14 de abril de 1941.

BRAUNER, V. L. Desafios emergentes acerca do empoderamento da mulher através do esporte. Movimento, Porto Alegre, v. 21, n. 2, p. 521-532, abr./ jun. 2015.

BRAWLEY, L. R.; CARRON, A. V.; WILDMEYER, W. N. The influence of the group and its cohesiveness on perceptions of group-related variables. Journal of Sport and Exercise Psychology, v. 15, p. 245-260, 1993.

DARIDO, S. C. Futebol Feminino no Brasil: do seu início à prática pedagógica. Revista Motriz, Rio Claro, v. 8, n. 2, p. 43-49, 2002.

DEVIDE, F. P. Gênero e mulheres no esporte: história das mulheres nos jogos olímpicos modernos. Ijuí: UNIJUÍ, 2005.

DUNNING, E. Sport as a male preserve: notes on the social sources of masculine identity and its transformations. Women, sport, and culture. Human Kinetics, Champain, p.163-178, 1994.

DUNNING, E.; MAGUIRE, J. Process-sociological notes on sport, gender relations and violence control. International Review for the Sociolog y of Sport, London, v. 31, n. 3, p. 296-321, 1996.

ECOTEN, M. C. F.; CORSETTI, B. A mulher no espaço do futebol: um estudo a partir de memórias de mulheres. Fazendo Gênero 9. Diásporas, Diversidades, Deslocamentos, 23 a 26 ago., 2010.

ENDLER, C. Caracterização do Futebol Feminino: Um estudo etnográfico em um Clube na cidade de Curitiba. 2004. Dissertação de Mestrado, UnicenP, Curitiba, 2004.

FRANZINI, F. Futebol é "coisa para macho"? Pequeno esboço para uma história das mulheres no país do futebol. Rev. Bras. Hist., São Paulo, v. 25, n. 50, p. 315-328, Dec., 2005.

FUTEBOL FEMININO NO BRASIL - A História. Última Divisão, 2019. Disponível em: https://www.ultimadivisao.com.br/futebol-feminino-nobrasil-a-historia/. Acesso em: 06 ago. 2019.

GAllahuE, D. L.; OZMUN, J. C. Compreendendo o Desenvolvimento Motor: bebês, crianças, adolescentes e adultos. São Paulo: Phorte, 2003. 
GEOVANA, M. A gritante diferença salarial entre mulheres e homens no futebol. Alma Preta, 2019. Disponível em: https://www.almapreta. com/editorias/o-quilombo/a-gritante-diferenca-salarial-entre-mulheres-ehomens-no-futebol. Acesso em: 13 de nov. de 2020

GOELLNER, S. V. Mulheres e futebol no Brasil: entre sombras e visibilidades. Rev. Bras. Educ. Fís. Esp., São Paulo, v. 19, n. 2, p. 143-15, abr/jun, 2005. GOELLNER, S. V. O Elegante Esporte da Rede: O Protagonismo Feminino no Voleibol Gaúcho dos Anos 50 e 60. Movimento, Porto Alegre, v. 12, n. 01, p. 153-171, jan./abr. 2006

HOROCHOVSKI, R. R.; MEIRELLES, G. Problematizando o conceito de empoderamento. Seminário Nacional Movimentos Sociais, Participação e Democracia. Florianópolis, 2007.

KNIJNIK, J. D.; VASCONCELLOS, E. Sem impedimento: o coração aberto das mulheres que calçam chuteira no Brasil. In: COZAC, J. (Org.). Com a cabeca na ponta da chuteira: ensaios de psicologia do esporte. São Paulo: Annablume, 2003. p. 7-89.

KOLNER, L. J. Heterosexuality as an organizing principle in women's sport. International Review for the Sociology of Sport, London, v. 30, n. 1, p. 61-77, 1995.

LIMA, N. C.; SOUSA, M. G. B. (In)visibilidade das mulheres nos campos de futebol: quebra de tabus e aplicação de sua presença no espaço público mediante a prática do esporte profissional. Revista Eptca, v. 18, n. 1. jan/ mar. 2016.

LUIZELLI, E. M. Futebol feminino. Disponível em http://www.duda.com. br/fut_fem/principal.htm. Acesso em: 2 out. 2019.

MARQUeS, M. G. Psicologia do Esporte: aspectos em que os atletas acreditam. Canoas: Ulbra, 2003.

MARTIN, E. A mulher no corpo: uma análise cultural da reprodução. Rio de Janeiro: Garamond, 2006.

MARTINS, L.; MORAES, L. O futebol feminino e sua inserção na mídia: a diferença que faz uma medalha de prata. Pensar a Prática, v. 10, n. 1, p. 69-82, 18 dez. 2014.

MATOS, M. I. S. Outras Histórias: as mulheres e estudos dos gêneros - percursos e possibilidades. In: MATOS, M. I. S.; SOLER, M. A. (orgs.). Gênero em Debate: Trajetória e Perspectivas na Historiografia Contemporânea. São Paulo: Educ, 1997. p.85-114.

MOURÃO, L. Representação Social da Mulher Brasileira nas Atividades Físico-Desportivas: da Segregação à Democratização. Movimento, a. VII, n. 13 , p. $05-18,2000$.

MOURÃO, L. As narrativas sobre o futebol feminino: o discurso da mídia impressa em campo. Rev. Bras. Cien. Esporte, Campinas, v. 26, n. 2, jan. 2005

MULHERES entram em campo. Zero Hora, Porto Alegre, 2 fev. 2003. Caderno Esportes, p.40-42.

NUNAN, A. Homossexualidade: do preconceito aos padrões de consumo. Rio de Janeiro: Caravansarai, 2003.

PERROT, M. As mulheres ou os silêncios da história. Bauru: EDUSC, 2005.

ROCHA, J. X. S. Futebol feminino sob a ótica do preconceito de gênero. 2017. 54 f. Trabalho de Conclusão de Curso. Universidade Federal de Minas Gerais. Belo Horizonte, 2017.

RUBIO, K. A psicologia do esporte: histórico e áreas de atuação e pesquisa. Psicol. cienc. prof., Brasília, v. 19, n. 3, p. 60-69, 1999.

RUBIO, K. Ética e compromisso social na psicologia do esporte. Psicol. cienc. prof., Brasília, v. 27, n. 2, p. 304-315, jun. 2007.

RUBIO, K. Psicologia do Esporte: Interfaces, Pesquisa e Intervenção. São Paulo: Casa do Psicólogo, 2000.

SACALON, R. M.; BECKER JR.; B.; BRAUNER. M. R. G. Fatores Motivacionais que influem na aderência do programa de iniciação desportiva pela criança. Perfil, a. 3, n. 3, 1999.
SAMULSKI, D. M. Psicologia do esporte: manual para educação física, psicologia e fisioterapia. São Paulo: Manole, 2002.

SERPA, S. Treinar jovens: complexidade, exigência e responsabilidade. Revista da Educação Física, UEM, Maringá, v. 14, n. 1, p. 75-82. 2003.

SILVA, J. H. R. Gênero e Futebol: os desafios das mulheres na luta por reconhecimento social. Revista Digital, Buenos Aires, n. 175, dez. 2012.

TEIXEIRA, F. L. S.; CAMINHA. I. O. Preconceito no futebol feminino brasileiro: uma revisão sistemática. Movimento, Porto Alegre, v. 19, n. 1, p. 265-287, Jan/mar. 2013.

TOJAL, M. C. Corpo de mulher e poder: relações de gênero. Lato \& Sensu, Belém, v. 4, n. 1, p. 1-8, out 2003.

VALLERAND, R. J. On the psychology of passion: in search of what makes people's lives most worth living. Canadian Psychology, Winnipeg, v. 49, n. 1,2008 .

VILANI, L. H. P.; SAMULSKI, D. M. Família e esporte: uma revisão sobre a influência dos pais na carreira esportiva de crianças e adolescente. In: SILAMI GARCIA, E.; LEMOS, K. L. M. Temas atuais VII: Educação Física e Esportes. Belo Horizonte: Health, 2002. p. 09-26.

WEINBERG, R. S.; GOULD, D. Foundations of sport and exercise psychology. Champaign, IL: Human Kinetics, 1995.

WEINBERG, R. S.; GOULD, D. Fundamentos da Psicologia do Esporte e do Exercício. 2. ed. Porto Alegre: Artmed, 2001.

WILliAnS, J. M.; STRAUB, W. F. Nueva Psicologia del Deporte: Pasado, Presente, Futuro. In: WILLIANS, J. M. (org.). Psicologia Aplicada al Deporte. Madrid: Biblioteca, 1991

ZANETTI, M. C.; LAVOURA, T. N.; MACHADO, A. A. Motivação no esporte infanto juvenil. Conexões, v. 6, 2008.

ZEFERINO, J. C.; SALLES, J. G. C. Protagonismo feminino no esporte universitário: reflexões a partir das teorias elisianas e feminista. Civilização e Contemporaneidade. XII Simpósio Internacional Processo Civilizador, Recife, 10 a 13 nov., 2009. 